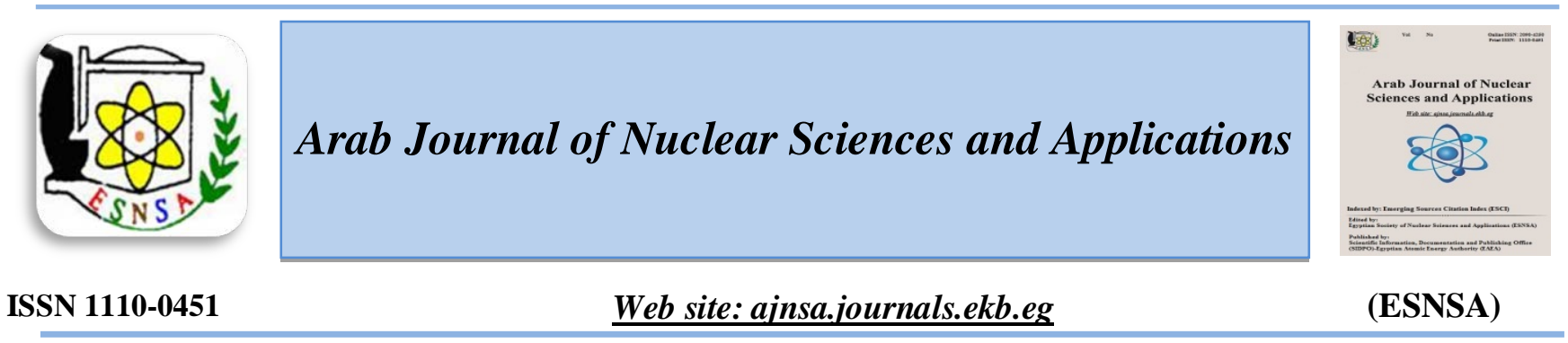

\title{
Thermoluminescence and Kinetic Analysis of Some Gamma Irradiated Rocks from Makkah, Saudi Arabia
}

\author{
H. S. Hafez ${ }^{1}$, A. A. Hendi ${ }^{2}$, and Lamis A. Attia ${ }^{1}$ \\ ${ }^{1}$ Radiation Protection Department, Nuclear Research Center, Egyptian Atomic Energy Authority; \\ ${ }^{2}$ Physics Department, Science Faculty for Girls, King Abdulaziz University, Jeddah, Saudi Arabia
}

\begin{abstract}
Received $1^{\text {st }}$ Mar 2018 In the present work, some rocks were collected from Makkah, Saudi Arabia. Thermoluminescence Accepted $15^{\text {th }}$ Dec. 2018 technique was utilized to investigate the possibility of using the samples as an accidental radiation dosimeter. After $\gamma$-ray irradiation by Co-60 source, Makkah rocks sample revealed a $\mathrm{TL}^{-p e a k}$ at $155^{\circ} \mathrm{C}$. The peak position is decreased with the increase of the $\gamma$-dose. The chemical analysis of Makkah rocks was conducted using the XRF technique. The natural fading, the effect of temperature on the ability of the samples to be stored, the TL-signal and the optimum grain size of the samples were studied. The activation energy was calculated using the peak shape method. The TL-signal exhibits a linear response through the gamma dose range $\mathbf{0 . 0 1 - 1 k} \mathrm{Gy}$. In this range of exposure, the sample under study can be considered as an accidental dosimeter.
\end{abstract}

Keywords: Thermoluminescence, Fading, Radiation dosimetry, Kinetic parameters Makkah Gabbro rocks

\section{Introduction}

Thermoluminescence is the main physical technique used in the field of radiation dosimetry. Some natural and synthetic samples exhibit thermoluminecent properties under suitable conditions of thermal stimulation. The thermoluminscent properties for natural samples depend on their location, history, impurities and composition [1-5].

Thiago Michel de Brito Farias, and Shigueo Watanabe [6] investigated the thermoluminescence properties of a variety of natural quartz, such as the blue, the green, the red, the pink, the black, the sulphurous and the milky quartz. The TL peaks at 110, 175, 220, 325 and $375{ }^{\circ} \mathrm{C}$ observed in the alpha quartz were not found in all these varieties of quartz. As for the TL response as a function of gamma ray dose, a quite different behavior has been observed and discussed.
Ki-Bum Kim, and Duk-Geun Hong [7] reported that Calcite has been of particular interest in studies of thermoluminescence (TL) because of its geological and archeological importance. Although extensive research on the TL glow curves of calcite has been conducted, most previous works have been based on the TL intensity integrated over a particular temperature range on the glow curve, without any separation of peaks. These researches involved the investigation of the physical characteristics of the overlapping peaks in the TL glow curves of a calcite sample.

These properties can provide useful information for determining the radiation dose absorbed to the sample in radiation dosimetry and luminescence dating research. The Tm-Tstop method is employed to identify the number of hidden glow peaks, and the kinetic parameters of each separated 
glow peak, including the thermal activation energy, the kinetic order, and frequency factor, are evaluated using a computerized glow curve deconvolution (CGCD) method.

H.L. Sullasi et al. [8] found out that the TL glow curve of the larimar rock in the natural conditions shows the presence of a broad signal between 80 and $170^{\circ} \mathrm{C}$ and a peak around $280^{\circ} \mathrm{C}$. The intensity of the TL peak at $280^{\circ} \mathrm{C}$, as a function of radiation dose, presents a linear behavior up to $2500 \mathrm{~Gy}$. The TL emission of this peak shows a band around $580 \mathrm{~nm}$. A fading effect of around $25 \%$ is observed after one month.

Rocks from Makkah area, Saudi Arabia was studied in present work to investigate its TLproperties. The kinetic parameters of the samples were calculated.

\section{Methods and Samples Preparation}

The rocks were collected from near King Fahd road, the Makkah area in Saudi Arabia Figure (1. $\mathrm{a}, \mathrm{b})$. The rocks were washed with distilled water to remove the organic materials [9-11]. The samples were crushed in a ceramic mortar and sieved through several meshes (300, 212, 106 and $53 \mu \mathrm{m})$. Samples of different sizes were exposed to 100 Gy from a Co-60 gamma source (dose rate $21.88 \mathrm{~Gy} / \mathrm{min}$ ). The samples were read out in the TL-reader at a heating rate of $50 \mathrm{C} / \mathrm{sec}$.

Fading characteristics of the thermoluminescence (TL) signal of the rock samples were studied at the ambient laboratory temperature for 83 days. Other samples have been stored at different temperatures (50 and 100oC) for different periods of times (1, 3, $24 \mathrm{hr}$ ) after irradiating them at $100 \mathrm{~Gy}$ gamma ray. Samples were irradiated with different gamma doses to study the dependence of the TL-signal on the different dose values [12].
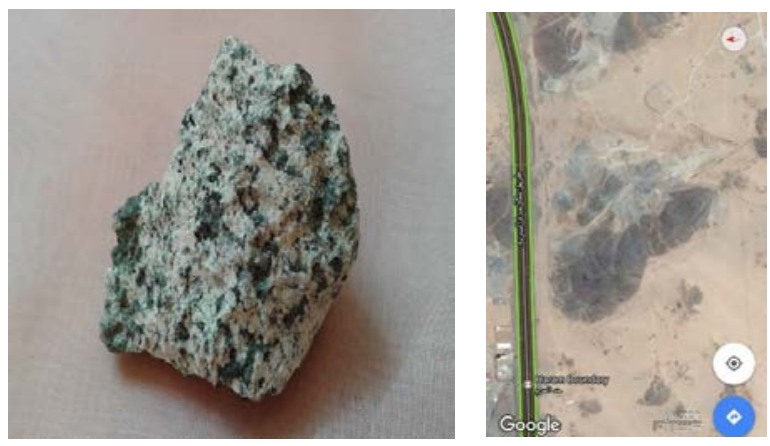

Figure (1. a, b). (a) Location of collected sample from Fahd road, Makkah area in Saudi Arabia and (b) Makkah Rock Sample
A powder sample $(5 \mathrm{mg})$ is packed into an aluminum holder to determine the chemical compositions using X-ray fluorescence (XRF) technique model (JSX-3222 analyzer). High accuracy analysis was performed using a detector featuring high energy resolution (149 eV or less). A powerful X-ray source (50 kV, $1 \mathrm{~mA}, 50 \mathrm{~W})$ for speedy, accurate analysis. Analysis was conducted on samples of grain size ranging from macro (14mm dia.) to micro (300 $\mu \mathrm{m}$ dia., option). Surface morphology of the samples was recorded using a scanning electron microscope (SEM) model (JEOL JSM 5600 LV). The electron-optical column together with associated electronics, the vacuum system including the specimen chamber and stage, the final group consists of the signal detection and display systems.

\section{Results and Discussion}

\section{Grain size and chemical composition}

The TL-sensitivity of different grain size samples was studied. From the experimental results the decrease of the grain size increases the TLsensitivity. Therefore, grain size range $53-106 \mu \mathrm{m}$ is selected for studying the rock under investigation. This may be due to the good contact with the heating tray in case of small sizes. The big grain size may cause self-absorption to the luminescence and prevent the light emitted from the sample to reach to the photomultiplier [13].

Using the XRF technique revealed the elemental analysis pattern of the sample as shown in Figure (2). The chemical composition of the sample is given in Tables $(1 \& 2)$. All the elements in these tables are presented as oxides. Table (1) shows high concentrations of $\mathrm{SiO} 2$ (45.41\%), while Table (2) shows some rare earth element concentrations.

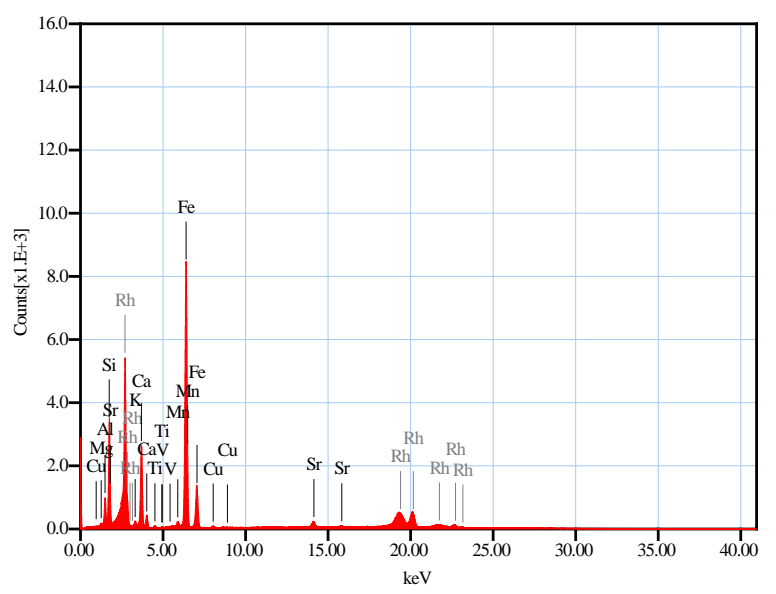

Figure (2): The XRF analysis of Makkah rock 
Table (1) The chemical composition of Makkah rock

\begin{tabular}{|l|l|l|l|l|l|l|l|l|}
\hline Compound & $\mathrm{SiO}_{2}$ & $\mathrm{Al}_{2} \mathrm{O}_{3}$ & $\mathrm{Fe}_{2} \mathrm{O}_{3}$ & $\mathrm{~K}_{2} \mathrm{O}$ & $\mathrm{CaO}$ & $\mathrm{CuO}$ & $\mathrm{MnO}$ & $\mathrm{MgO}$ \\
\hline Wt, \% & 45.41 & 19.52 & 15.45 & 0.80 & 13.39 & 0.07 & 0.34 & 4.56 \\
\hline
\end{tabular}

Table (2) Concentrations of Other elements of Makkah rock

\begin{tabular}{|l|l|l|l|}
\hline Metal & $\mathrm{Ti}$ & $\mathrm{V}$ & $\mathrm{Sr}$ \\
\hline Wt. \% & 0.36 & 0.07 & 0.189 \\
\hline
\end{tabular}

The results are in a satisfactory agreement with the data of the mineralogical composition of the Gabbro rocks in previous studies [14].

From the chemical composition, the presence of $\mathrm{Al} 2 \mathrm{O} 3$ refers to an excess of feldspar which exhibits a thermoluminescent phenomenon [1517]. Also, the inclusion of rare earth elements in the rock may enhance the TL-sensitivity of the sample [13].

The scanning electron micrographs clearly reveal the surface texture and morphology of the sample as shown in Figure (3). The surface morphology of the rock of interest showed that its appearance is angular to sub-rounded with smooth edges and sides. The sample shape is irregular and its surface is porous.

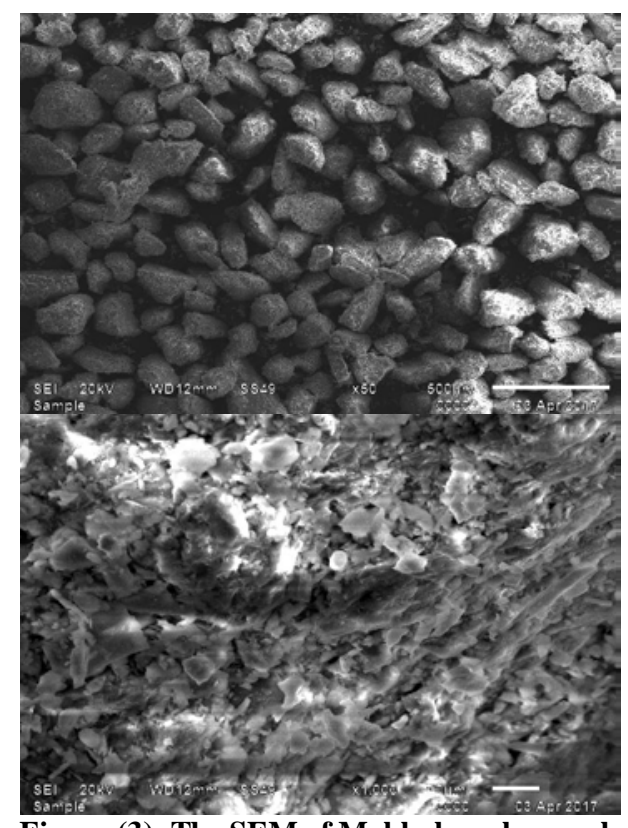

Figure (3): The SEM of Makkah rock sample

\section{Glow curve}

Figure (4) illustrates the TL-glow curve of natural Makkah rock sample (unirradiated) which has total TL-Intensity (area under the curve) of $423 \mathrm{nC}$. These glow curves are attributed to irradiation from a number of natural sources which include self-irradiation, from surrounding geological formations and cosmic sources [5]. The total TLIntensity may have suffered thermal fading due to the high temperature of the Makkah area. Of course, these peaks will be regenerated with gamma radiation doses.

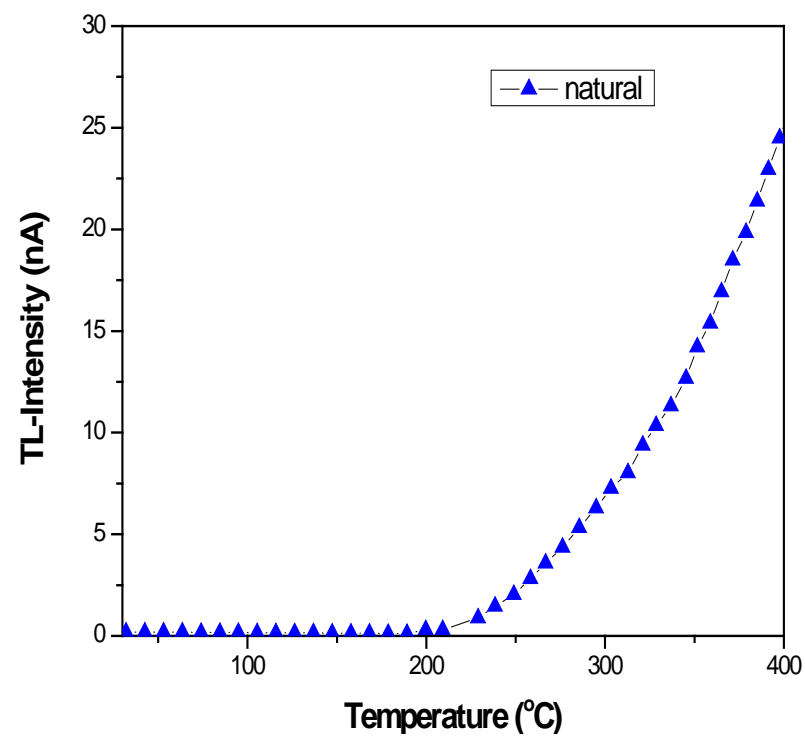

Figure (4): The TL- glow curve of natural Makkah rock (unirradiated) of grain size $(53-106 \mu \mathrm{m})$

The sample of Makkah rocks which was gamma irradiated (10Gy-10kGy) have the main peak at $155^{\circ} \mathrm{C}\left(\mathrm{P}_{1}\right)$ and the remainder raise part of the glow curve may call it as peak $2\left(\mathrm{P}_{2}\right)$ as shown in Figure(5). The TL-Intensity of the samples increase with the increase of $\gamma$-dose. 


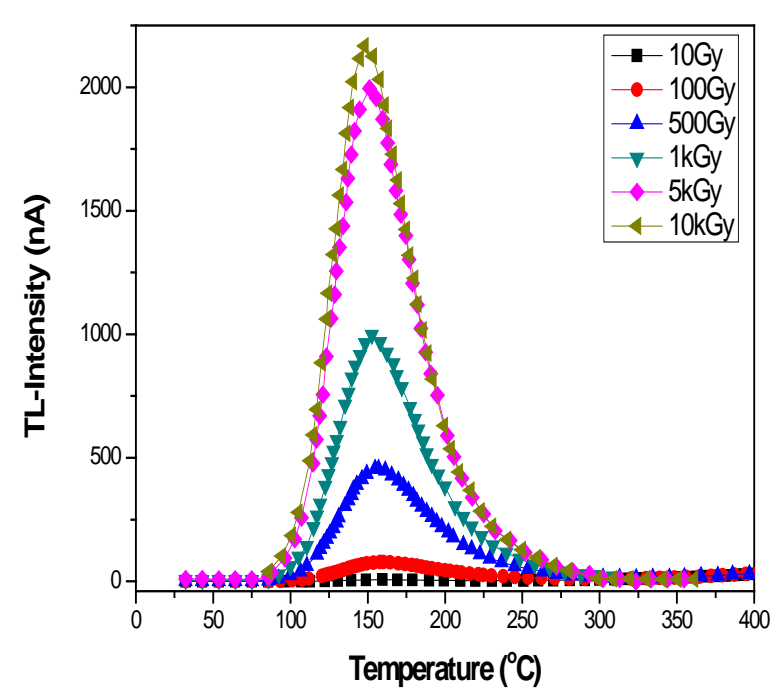

Figure (5): The glow curves of the samples irradiated with $\gamma$ ray from $10 \mathrm{~Gy}$ up to $10 \mathrm{kGy}$

The peak position (P.P.) was shifted to the lower temperature with the $\gamma$-dose (D) increased as shown in Figure (6).

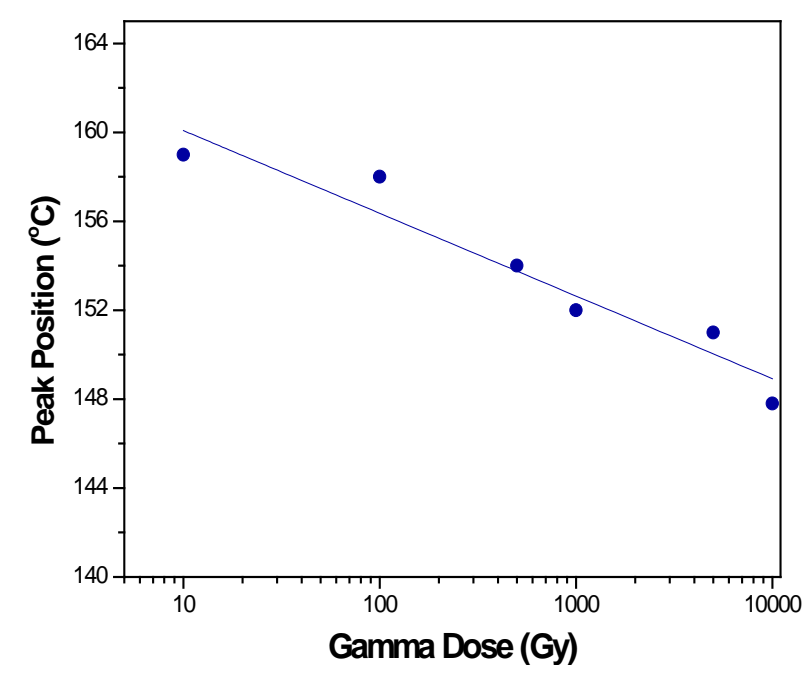

Figure (6): The relation of the peak position shift with the increase of the $\gamma$-dose

This observation can be represented by the following semi-empirical formula:

$$
\text { P.P. }\left({ }^{\circ} \mathrm{C}\right)=-3.72 \log \mathrm{D}(\mathrm{Gy})+163.8
$$

The shift of the peak to lower temperature with the increase of doses may be due to the tendency of the electrons to fill the deep energy levels of the same trap. This effect is shown as peak shifting to lower temperature [13].

\section{The response curve}

A relation between different gamma doses (10Gy 10KGy) and the corresponding total TL-intensity of the sample is illustrated in Figure (7).

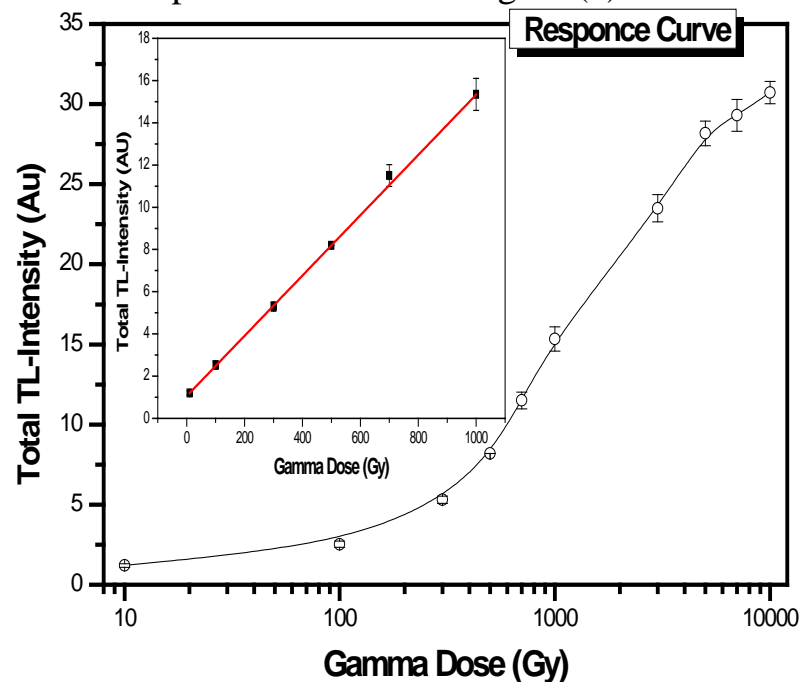

Figure (7): The response curve of Makkah samples

The dose response function is defined as the functional dependence of the intensity (I) of the measured TL signal on the absorbed dose (D). Because an ideal dosimetric material must have a linear dose response over a wide range, most TL materials can be used as effective dosimeters within a certain range of doses $[1,18]$. From the figure, the TL response in the range $0.01-1 \mathrm{kGy}$ follows the linear empirical formula:

$\mathrm{I}=0.014 \mathrm{D}+1.057$

While the TL response in the range 3-10 kGy follows the exponential empirical formula:

$I=-29.213 e^{-D / 2158.875}+30.82$.

The linear region may be used in high doses radiation measurement. Makkah sample may be suitable for dosimetry in the main radiation processes of seed stimulation, mutation breeding, industrial radiography, and pasteurization and water purification [11].

\section{Kinetic parameters}

The activation energy has been calculated using the Chen peak shape method for general order kinetics [13, 19] according to the following equation: 
$\mathrm{E}=\mathrm{c}_{\gamma}\left(\mathrm{k} \mathrm{T}_{\mathrm{m}}^{2} / \gamma\right)-\mathrm{b}_{\gamma}\left(2 \mathrm{kT}_{\mathrm{m}}\right)$

Where $\gamma$ stands for $\tau$, the half-width at the low temperature side, $\delta$, the half-width at the fall-off side or $\omega$, the total half-width of a glow peak. The values of $c_{\gamma}$ and $b_{\gamma}$ are summarized in Table (3), and $\mu=\delta / \omega$, is the symmetry factor

Table (3): Values for the constants $c_{\gamma}$ and $b_{\gamma}$ in equation (4) for the general-order case

\begin{tabular}{|lll|}
$\gamma$ & $c \gamma$ & $b \gamma$ \\
\hline$\tau$ & $1.51+3(\mu \mathrm{g}-0.42)$ & $1.58+4.2(\mu \mathrm{g}-0.42)$ \\
$\delta$ & $0.976+7.3(\mu \mathrm{g}-0.42)$ & 0 \\
$\omega$ & $2.52+10.2(\mu \mathrm{g}-0.42)$ & 1.0 \\
\hline
\end{tabular}

The frequency factor (s) has been calculated using Urbach, 1930 [13] equation:

$$
\text { i.e., } \mathrm{s}=\left[\beta \mathrm{E} / \mathrm{kT}_{\mathrm{m}}{ }^{2}\right] \exp \left(\mathrm{E} / \mathrm{kT}_{\mathrm{m}}\right)
$$

where $\beta$ is the heating rate.

Table (4) shows that, the sample peak is second order (where $\mu=0.571$ ). The activation energy is $0.920 \pm 0.036 \mathrm{eV}$ and the frequency factor is $2.759 \times 10^{10} \mathrm{~s}^{-1}$. The activation energy value of the peak sample is deep enough to be used as a dosemetric peak.

\section{The natural fading}

The sample under investigation was exposed to gamma dose $100 \mathrm{~Gy}$ and stored in opaque box at room temperature. Several TL-readings were evaluated after different intervals of time up to 83 days in average room temperature $17^{\circ} \mathrm{C}$. The TLsignal of $\mathrm{P}_{1}, \mathrm{P}_{2}$ and the total area under the curve against the storage time illustrated in Figure (8). From the figure, $94.6 \%$ from the initial TL-signal were still during 83 days. This result indicates that Makkah rocks sample can store the energy for a long time.

Figure (8) shows that, p1 decreases with the increases of the storage time. This may be due to the effect of the ambient temperature. Whereas, p2 increase with the time, which may be increased by means of, retrapping of TL-energy released from p1.

\section{The effect of heat on the TL-signal fading}

The sample irradiated with 100 Gy gamma rays is represented by the glow curve 1 in Figs. (9-a) and (10-a). Curve 1 has TL-glow peak at $154^{\circ} \mathrm{C}(\mathrm{p} 1)$ and the remainder raise part of p2. Parts of the irradiated samples were stored in an oven at 50 and $100^{\circ} \mathrm{C}$ for 1,3 and $24 \mathrm{~h}$. These are represented by curves 2, 3 and 4 respectively in Figs. (9-a) and (10-a). Figures (9-b) and (10-b) represent the relation between the storage time at 50 and $100^{\circ} \mathrm{C}$ and the corresponding area under the curve of $\mathrm{p} 1$, p2 and the total area under the curve for the two cases. From Figs. (9-b and 9-b) p1 decreased as the storage time increased until reach to $33 \%$ and $11 \%$ of the initial TL-signal after $24 \mathrm{~h}$ respectively. While, p2 increased with the increasing of the storage time until multiplied 5 and 2.5 time than the initial TL-signal in the two cases respectively. The increase of p2 may be occurred due to the retrapping of the escaped electrons from other peaks with the temperature effect. The total area under the curve in case of $50^{\circ} \mathrm{C}$ increased with the increase of the storage time to reaching 1.6 time of its initial TL- intensity after $24 \mathrm{~h}$. While in case of $100^{\circ} \mathrm{C}$, the total area under the curve decreased to $82 \%$ from the initial TL-signal.

Table (4): Calculation of the activation energy (E) and frequency factor (s) by using peak shape method

\begin{tabular}{|c|c|c|c|c|c|c|c|c|c|}
\hline \multirow{2}{*}{$\begin{array}{l}\mathrm{T}_{\mathrm{m}} \\
\left({ }^{\mathrm{o}} \mathrm{K}\right)\end{array}$} & \multicolumn{4}{|c|}{$\mathrm{C}_{\gamma}{ }^{0} \mathrm{~K}$} & \multicolumn{3}{|c|}{$\mathrm{E}\left(\mathrm{C}_{\gamma}\right) \mathrm{eV}$} & \multirow{2}{*}{$\begin{array}{l}{[\mathrm{E}(\delta)+\mathrm{E}(\tau)} \\
+\mathrm{E}(\omega)] / 3 \mathrm{E}(\mathrm{ev})\end{array}$} & \multirow{2}{*}{$\begin{array}{l}\text { Frequency } \\
\text { factor } s\left(s^{-1}\right)\end{array}$} \\
\hline & $\tau$ & $\delta$ & $\omega$ & $\mu$ & $\mathrm{E}(\tau)$ & $\mathrm{E}(\delta)$ & $\mathrm{E}(\omega)$ & & \\
\hline 422 & 27 & 36 & 63 & 0.571 & 0.957 & 0.886 & 0.917 & $0.920 \pm 0.036$ & $2.759 \times 10^{10}$ \\
\hline
\end{tabular}




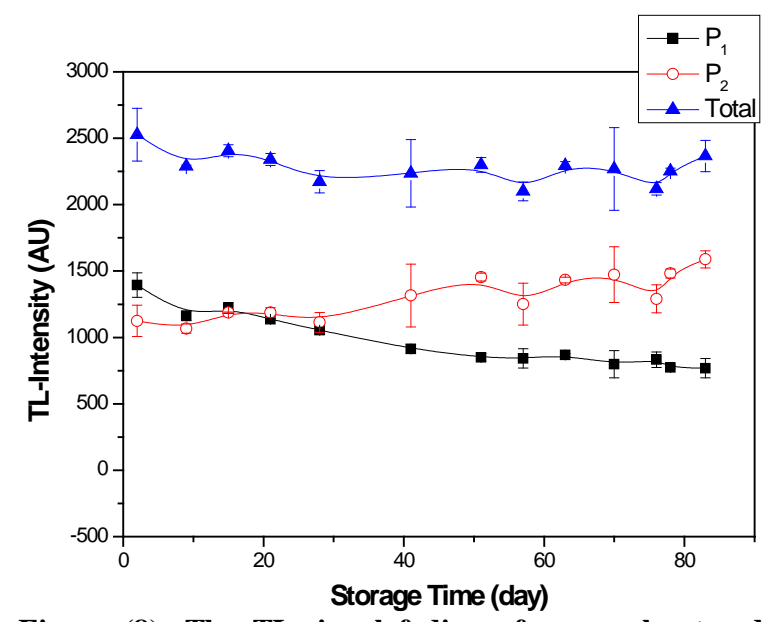

Figure (8): The TL-signal fading of a sample stored at room temperature after irradiation at $100 \mathrm{~Gy} \gamma$-ray, P1, $P 2$ and total area under the curve
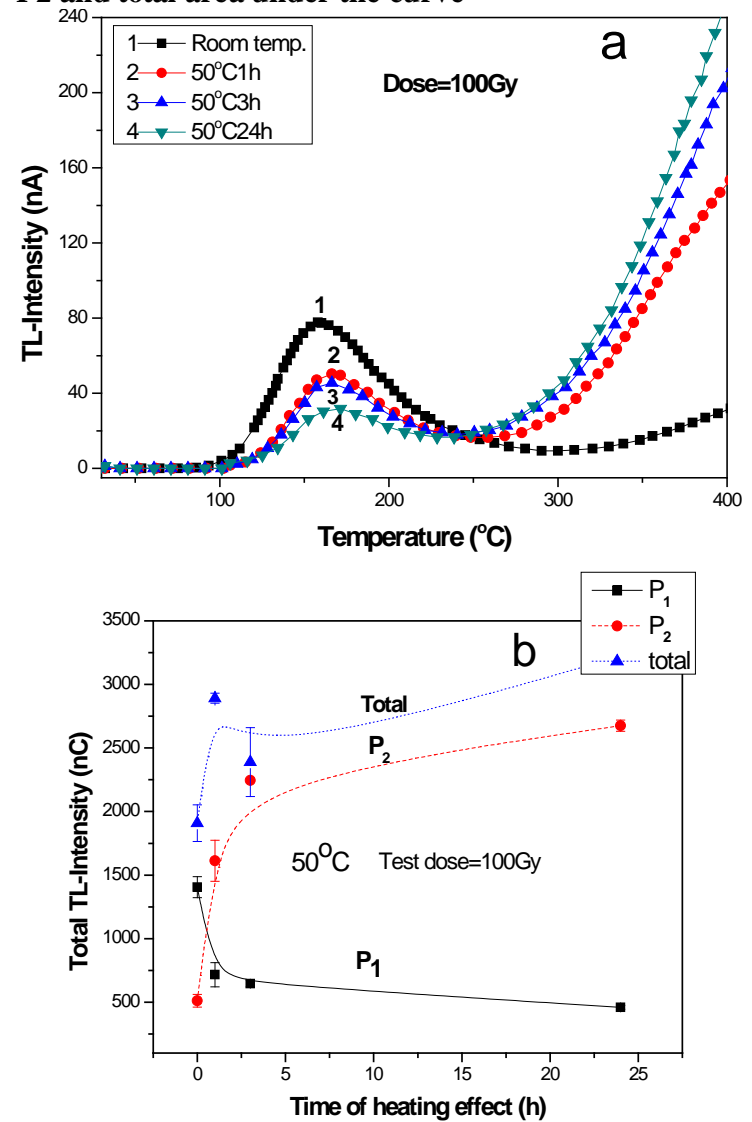

Figure (9. a, b): (a) The glow curves of Makkah samples were irradiated by $100 \mathrm{~Gy}$ and other samples read after stored it in $50^{\circ} \mathrm{C}$ for 1,3 and $24 \mathrm{~h}$. (b) The relation between the storage time and the area under the curve of $p 1, p 2$ and the total curve
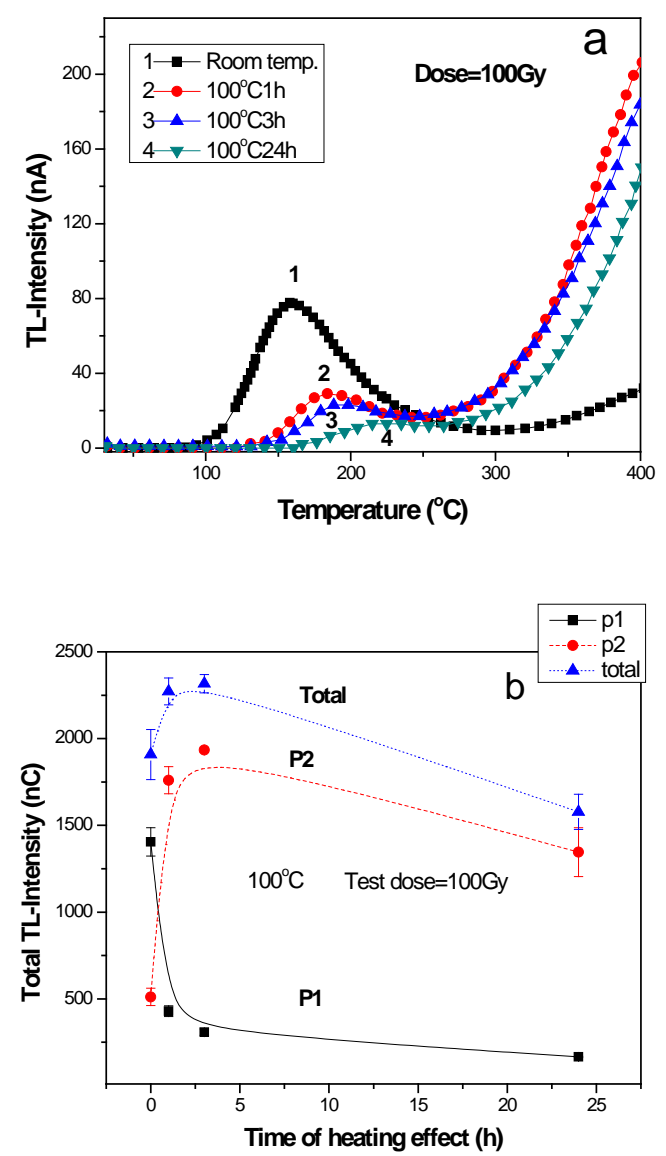

Figure (10. a, b): (a) The glow curves of Makkah samples were irradiated by $100 \mathrm{~Gy}$ and other samples read after stored it in $100^{\circ} \mathrm{C}$ for 1,3 and $24 \mathrm{~h}$. (b) The relation between the stored time and the area under the curve of p1, p2 and the total curve

\section{Conclusion}

Makkah rock samples show some TL-sensitivity. The main material of the sample is SiO (45.41\%) which exhibits TL-sensitivity. The presence of feldspar material and rare earth elements may enhance the TL-sensitivity of the sample. Makkah sample has a dosemitric peak at $155^{\circ} \mathrm{C}$ and part of composite another peak. By the study of the storage of the sample in high temperature (50 and 100 ), we noted that $\mathrm{p} 1$ decreased with the increase of temperature and the time of storage. Whereas, p2 increased with the increase of temperature and time of storage and decreased again with the increase of the time in case of $100^{\circ} \mathrm{C}$. This increase of the TL-intensity of the second peak may be due to the transport of electrons from the other peaks and the more tendency of it to retraped in $\mathrm{p} 2$. The sample can store the energy for a long time they have $94.6 \%$ from the initial TL-signal during 83days. The measuring of the kinetic parameters prove that the sample able to store the TL-signal 
which, agree with the experimental results. The dose response curve is linear in the range 0.01-1 kGy. From the above results, Makkah sample can be used in high dose radiation dosimetry.

\section{Acknowledgement}

The authors are grateful for the financial support from the Research Fund of Egyptian Atomic Energy Authority.

\section{References}

1- C. Soliman, S.M. Metwally, F.F. Alharbi, K.M. Elshokrofy,Behavior of Thermoluminescence Green and Red Emission Bands of Natural Dolomite Irradiated with Gamma Rays, Journal of Tiabah University of Science Volume 11, Issue 4, July 2017, Pages 534-539.

2- C. M. Sunta, Unraveling Thermoluminescence, Springer Series in Materials Science 202 (2015).

3- M. Topaksu, V.Correcher, J.G. Guinea, M. Yüksel, Effect of heating rate on the thermoluminescence and thermal properties of natural ulexite, Applied Radiation and Isotopes 95 (2015) 222-225

4- Z. Yegingil, N. Nur, T. Dogan, N. Yazici, M. Topaksu, Effects of annealing and high radiation dose on the thermoluminescence characteristics of natural fluorite, Radiation Measurements 47 (2012) 981-987.

5- F.O. Ogundare, F.A. Balogun, J.A. Olowofela, C.E.Mokobia,O.O.Fasunwon,Thermoluminesce -nce characteristics of natural dolerite, Nuclear Instruments and Methods in Physics Research Section B: Beam Interactions with Materials and Atoms,Volume 243, Issue 1, January 2006, Pages 156-160.

6- Thiago Michel de Brito Farias, Shigueo Watanabe, A comparative study of the thermoluminescence properties of several varieties of Brazilian natural quartz, Journal of Luminescence 132 (2012) 2684-2692

7- Ki-Bum Kim, Duk-Geun Hong, Kinetic parameters, bleaching and radiation response of thermoluminescence glow peaks separated by deconvolution on Korean calcite, Radiation PhysicsandChemistry103(2014)16-21.

8- H.L. Sullasi, H.J. Khoury, V. Barros, R. Libonati, P.L. Guzzo, V. Asfora, R.E. DeAraujo , M. Capriles d, J. Reyes, Thermoluminescence response of the larimar rocks, Radiation Measurements 45 (2010) 540-542

9- H. S. Hafez, A. A. Hendi, and R. H. Alorainy "Thermoluminescence Properties of El-Khobar Sand and the Feasibility of Using It in Accidental Dosimetry” Journal of Nanoelectronics and Optoelectronics Vol. 10, 730-733, 2015.
10- Silviu jipa, laura monica gorghiu, crinela dumitrescu, traian zaharescu, adrian mantsch, REV. CHIM. (Bucharest), 62 No. 3, 2011 357358.

11- Maria Ine s Teixeira, Gilberto M. Ferraz, Linda V.E. Caldas, Journal of Applied Radiation and Isotopes 62 2005, 359-363.

12- S. G. Vijapurkar, R Raman and P. K. Bhatnagar, Radiation Measurements Vol. 29, No. 2, (1998) pp. 223-226.

13- Mckeever, S.W.S. (1988) “Thermluminescence of solids” Camb. Univ. Press, New York, New Rochelle, Melbourne Sydney.

14- I. Z. Babievskaya, N. F. Drobot, S. V. Fomichev, and V. A. Krenev, Evaluation of the Mineralogical Composition of Gabbro Rocks from Chemical Data, Inorganic Materials, 2011, Vol. 47, No. 6, pp. 633-636.

15- Mohamed Ahmed, Abeer Salah, Ahmed Ashour, Hanaa Hafez, Nabil El-Faramawy, Dosimetric properties of $\mathrm{Cr}$ doped $\mathrm{Al} 2 \mathrm{O} 3$ nanophosphors, Journal of Luminescence 196 (2018) 449-454

16- George S. Polymeris, Vasilis Pagonis, George Kitis, Thermoluminescence glow curves in preheated feldspar samples: An interpretation based on random defect distributions, Radiation Measurements 97 (2017) 20-27.

17- Jae-Jun Ahn, Kashif Akram, Ji-Young Kwak, Mi-Seon Jeong, Yun-Deuk Jang, Joong-Ho Kwon, Radiation-induced thermoluminescence characteristics of feldspar upon different heat and microwave treatments, Journal of Luminescence 132 (2012) 1964-1968.

18- R. Chen, S.W.S. McKeever, Theory of Thermoluminescence and Related Phenomena, World Scientific, 1997.

19- J.M. Kalita n, G.Wary, Trap and recombination sites of biotite mineral estimated by thermoluminescence analysis, Journal of Luminescence170 (2016) 64-71. 